\title{
Valoración de una propuesta didáctica de actividades físicas en el medio natural fundamentada en el uso de la realidad aumentada Assessment of a didactic proposal on physical activities in the natural environment based on the use of augmented reality
}

Carlos Peñar rubia-Lozano, AnaTabuenca-Castejón, Inma Canales-Lacruz Universidad de Zaragoza (España)

Resumen: En losúltimos años se ha incrementado el número de estudios que incorporan el uso de la realidad aumentada en el ámbito educativo. Se han encontrado estudios contextualizados en diferentes etapasy áreas de conocimiento. En este estudio se expone una experiencia didáctica de Educación Física en un col egio de la ciudad de Zaragoza (España) fundamentada en el uso de lasTIC, especialmente en la realidad aumentada. Los contenidos seleccionados son la orientación y la escalada. Han participado en ella 37 estudiantes, con edades comprendidas entre los 10 y los 11 años. Ninguno de ellos contaba con experiencia previaen esterecurso didáctico en el contexto escolar. M edianteun diseño cual itativo, se haanalizado la percepción que esta tecnología ha suscitado en el alumnado. Los resultados son altamente positivos, destacando la intriga y la utilidad como principales motivos de satisfacción. Por otra parte, se han señalado los fallos en la conectividad como principal fuente de insatisfacción.

Palabras clave: A prendizaje, recurso didáctico, realidad aumentada, Educación Primaria, comportamiento del alumno.

\begin{abstract}
In recent years the number of studies that incorporate the use of augmented reality in the educational field has increased. Contextualized studies have been found in different stages and areas of knowledge. An educational experiment in the Physical Education domain is exposed in this study carried out in a school in the city of Zaragoza (Spain) based on the use of ICT, especially augmented reality. Selected contents are orienteering and climbing. Participants include 37 students, between the age of 10 and 11. None of them had previous experience in this educational tool at school. $0 \mathrm{n}$ the basis of qualitative methodology, the opinion that this technology has aroused in students has been analyzed. Results are highly positive, standing out intrigue and utility as the main reasonsfor satisfaction. $0 \mathrm{n}$ the other hand, connectivity failures have been pointed out as the main source of dissatiffaction.
\end{abstract}

Keywords: Learning, educational tool, augmented reality, Primary Education, student behaviour.

\section{Introducción}

\section{La realidad aumentada como herramienta di- dáctica}

La realidad aumentada (en adelante, $R A$ ) es una tecnología que permite superponer sobre diferentes elementos físicos, generalmente imágenes, información digital (Fombona, Pascual \& Madeira, 2012; Prendes, 2015). En otras palabras, y de acuerdo conAzuma(1997), se puede afirmar que ante un mismo objeto coexiste información virtual y real. Para su funcionamiento, Cabero y Barroso (2016) determinan una serie de elementos necesarios: el hardware (tablet, ordenador, Smartphone, videoconsola) con cámara de captura de imágenes; un dispositivo que permita proyectar las imá genes capturadas, que pueden coincidir con los cuatro

Fecha recepción: 05-08-20. Fecha de aceptación: 28-12-20

Carlos Peñarrubia-Lozano

carlospl@unizar.es elementos citados anteriormente; el programa 0 aplicación específica de RA; los activadores de la información de la $R A$ (códigos $Q R$, imágenes o GPS, en función del nivel en el que se enmarque la experiencia); y un servidor que permita almacenar la información virtual asociada a los marcadores.

El nivel de interactividad entre el objeto real y la información aumentada permite establecer cuatro niveles diferentes de RA (Estebanell, Ferrés, Cornellá \& Codina, 2012; Fombona, Pascual \& M adeira, 2012; Prendes, 2015), tal y como se expone a continuación:

- Nivel 0. Se corresponde con hiperenlaces que llevan al usuario a direccionesW eb o bien proporcionan información en forma de texto o de sonido. El ejemplo más destacado en este nivel son los códigos de respuesta rápida, QR.

- Nivel 1. En este nivel se utilizan marcadores, generalmente imágenes, que sirven como enlace para acceder a la información aumentada.

- Nivel 2. Incorpora la geolocalización. Gracias a las brújulas y GPS integrados en los dispositivos móvi- 
les, el software aumentado procesa la ubicación exacta del dispositivo y superpone en ella elementos de interés.

- Nivel 3. Requiere de dispositivos como gafas 0 cascos que favorecen una visión aumentada, de manera que la experiencia pueda ser más inmersiva y personal.

En los últimos años se ha incrementado el número de publicaciones sobre experiencias que incorporan esta tecnología en el ámbito educativo. Dada su versatilidad y capacidad de adaptarse a las diferentes edades y desa rrollo cognitivo de los participantes (Villalustre, Del Moral, Neira \& Herrero, 2017), su aparición ha irrumpido en todas las etapas formativas y en diferentes áreas de conocimiento. Así, se han encontrado experiencias en educación infantil, educación primaria (en adelante, EP), educación secundaria y universidad (Maquilón, Mirete \& Avilés, 2017). Destacan las Ciencias de la $N$ aturaleza como área de conocimiento en la que más experiencias se han analizado (Toledo \& Sánchez, 2017), seguida de Ciencias Sociales (CaldeiroPedreira, Yot-D omínguez \& Castro-Zubizarreta, 2018). Con un menor número de publicaciones aparecen representadas las áreas de Lengua y de idiomas extranjeros, así como Música(Amaya\& Santoyo, 2017). En Educación Física (en adelante, EF), se ha encontrado un incremento en el número de experiencias fundamentadas en el uso de la tecnología y de la RA como recurso didáctico (Calabuig-M oreno, Huertas, Fombona \& GarcíaTascón, 2020; Escaravajal \& Bæena, 2019). De esta forma, aparecen propuestas apoyadas en la lectura y creación de códigos QR (C astro \& Gómez, 2016; Izquierdo, 2013), actividades más inmersivas (GallegoLema, Muñoz-Cristóbal, Arribas-Cubero \& Rubia-Avi, 2017a) e, incluso, incorporando el componente de geolocalización (Pérez Amate \& Pérez O rdás, 2012).

La carrera de orientación aparece como el contenido más referenciado en la literatura. Pero lo reseñable es que no solo se ha trabajado desde el área de EF (Castro \& Gómez, 2016; Gallego-Lema, et al., 2017a; Moreno \& Pérez García, 2017; Pérez Amate \& Pérez 0 rdás, 2012). Por ejemplo, desde las Ciencias Sociales son varias las experiencias que utilizan los juegos de pistas como contexto para desarrollar determinados aprendizajes (Caldeiro-Pedreira, Yot-D omínguez \& Castro-Zubizarreta, 2018; Castañeda, Gutiérrez\& Román, 2014). Todo ello nos hace reflexionar sobre el reducido número de experiencias planteadas desde el área de EF. Másaún, cuando éstashan sido desar rolladas por alumnado universitario y los resultados obtenidos en las mismas indican que no solo han aprendido a utilizar las tecnolo- gías sino a diseñar y organizar una prueba de orienta ción.

Los estudios consultados ponen de manifiesto una serie de ventajas o de beneficios que la RA aporta en el contexto educativo. El principal motivo viene dado por la oportunidad de crear un entorno de aprendizaje que genere en los estudiantes una mayor motivación hacia el aprendizaje (Cabero \& Barroso, 2016; García \& Ra mos, 2016; Pedraza, Amado, Lass \& Munévar, 2017; Pérez-López, 2015). A su vez, esta actitud se traduce en una mejora en el rendimiento académico (Fombona \& Pascual, 2017). Finalmente, son muchos los autores que consideran que el uso de la RA en el contexto formativo favorece el desarrollo de una educación inclusiva, encontrando beneficios para diferentes realidades individuales de los estudiantes, como el Trastorno del Espectro Autista (Láinez, Chocarro De Luis, Busto \& López, 2018) o Síndrome de Down (M artín-Sabarís \& Brossy-Scaringi, 2017), señalando dificultades casi exclusivamente para estudiantes con discapacidad visual (Marín-Díaz, 2018).

Sin embargo, esta tecnología también tiene asocia da una serie de limitaciones, que pueden resumirse en los siguientes puntos: limitaciones técnicas derivadas de problemas de conectividad (San Pedro, Villalustre \& Herrero, 2019); la complejidad de las aplicaciones utilizadas (Leiva \& Moreno, 2015); aspectos económicos referidos tanto a la adquisición de dispositivos como a la contratación de líneas de servicios (Kim, Chun \& Lee, 2014); y las reticencias de los centros escolares a emplear los dispositivos móviles (Pérez Amate \& Pérez Ordás, 2012).

\section{Las actividades físicas en el medio natural en el currículo de EP}

Las actividades físicas en el medio natural (en adelante, AFMN) quedan recogidas en el marco legislativo curricular español (LOMCE, 2013) como uno de los cinco bloques de contenidos especificados para el área de EF. El diseño de la experiencia que se presenta en este trabajo se ha hecho tomando como referencia el currículo desar rollado en la Comunidad Autónoma de Aragón (Resolución de 12 de abril de 2016), en la que se ha llevado a cabo. De este modo, quedan definidas de la siguiente manera:

Las acciones básicas de este bloque (con o sin materiales) se efectúan en el entorno natural o similar, que puede presentar diversos niveles de incertidumbre y estar máso menos acondicionado, codificado o balizado. Las relaciones del alumnado y el medio natural suelen 
acarrear una implicación y compromiso total, lo que puede conllevar una fuerte carga emocional.

En este bloque se incluyen todas las situaciones con incertidumbre emergente del medio, tanto si el alumnado se enfrenta a ellas solo, en colaboración con otros participantes, o en oposición individual o grupal. Resulta decisiva la codificación de información de las condiciones del entorno para situarse, priorizar la seguridad sobre el riesgo y para regular la intensidad de los esfuerzos en función de las posibilidades personales.

Estas actividades facilitan la conexión con otras áreas del currículo y la profundización en valores relaciona dos con la conservación del entorno, fundamentalmente del medio natural. El senderismo, la marcha nórdica, las rutas en BTT, utilizar las vías verdes, las acampadas, las actividades de orientación, los grandes juegos en la naturaleza, lasactividadesen lanieve, latrepa (que puede evolucionar hacia la escalada), las actividades que combinan algunas de las anteriores prácticas físicas forman parte, entre otras, de las actividades de este bloque. (Anexo II, Área de EF, 2016, p.2.).

Aunque son muchos los estudios que han puesto de manifiesto los beneficios sobre las personas que las practican (Baena \& Graneros, 2015; Gehris, M yers \& W hitaker, 2012; Klein \& Carnicelli, 2009), las características propias de este bloque de actividades hacen que su presencia en los centros educativos pueda verse limitada. La dependencia de la meteorología, la necesidad de contar con materiales específicos o el desplaza miento al entorno natural son al gunos de los factores que afectan a este cometido (Peñarrubia, Guillén \& Lapetra, 2016). Sin embargo, en el currículo vigente para la etapa de EP se especifica que el desarrollo de estos contenidos va a depender de las posibilidades de cada centro escolar.

En la tabla 1 se presenta la relación entre criterios de evaluación, estándares de aprendizaje y competencias clave asociados a las AFM N como contenido de EF. La consideración que se especifica en el currículo sobre la posibilidad de aprovechar las características del centro, permite adoptar por parte del profesorado diferentes métodosparaafrontar laincertidumbre del espacio de prácticas. En losúltimos años han aparecido trabajos que han incorporado el uso de lasT IC como un recurso didáctico dentro de este bloque de contenidos (Gallego-Lema et al., 2017b). Dentro de las mismas, la RA puede permitir un acercamiento del alumnado a la práctica en un entorno natural, incluso sin salir del centro (GallegoLema et al. , 2017a; Peñarrubia, Q uintas, Rapún \& Falcón, 2018).
Tabla 1.

Desar rollo curricular de las AFM N en EP

Contenidos:

Actividades en el medio natural: el senderismo, la marcha nórdica las rutas en BTT, Ias acampadas, las actividades de orientación, los grandes juegos en la naturaleza, el esquí nórdico (y otras modalidades), la trepa (que puede evolucionar hacia la escalada), etc.

Adopción de una motricidad adaptada y específica para ajustarse a un medio variado y, a veces, variable (natural o reproducido) y para manejar instrumentos, vehículos o materiales que produzcan problemas de equilibrio; toma de informaciones y referencias pertinentes par construir un desplazamiento razonado y reflexionado; familiarización con materiales soporte (mapas, etc.); gestión y regulación de la energía con el fin de llegar a buen término una actividad en el medio natural con economía y eficacia; funcionamiento como grupo en una salida en el medio natural; principios de seguridad activa y pasiva; características de las rutas según MIDE; progresión en los espacios de la actividad, etc.

Trepa: tres apoyos, el centro de gravedad pegado a la pared, etc. Espacios de trabajo: escenarios con planos inclinados, espalderas, rocódromos, etc.

Esquí nórdico: aprendizajes para actuar del estilo clásico (paso alternativo, paso de subida, paso empuja, posición de bajada y cuña, paso combinado), regulación del esfuerzo en la actividad y aprendizajes para gestionar una práctica autónoma (uso de instalaciones y espacios, seguridad pasiva y activa, autonomía en la gestión del material).

BTT: U so de los cambios de manera autónoma para adaptarse a las particularidades del terreno, acciones específicas para adaptarse a las condiciones de la ruta (retos variados en formato taller como zigzag, trébol, taller de los lentos, juegos de equilibrio, el limbo, etc.), educación vial, principios de seguridad activa (comportamiento en ruta) y pasiva (cuidado y mantenimiento básico), indumentaria (casco, guantes, gafas, culote, etc.), funcionamientos como grupo en las salida, etc.

O rientación: conocimiento del plano, localización de puntos, orientación del plano, seguimiento de trayectorias, ataque a la baliza, uso de brújula, etc.

Roles de trabajo: anotador, participante, cronometrador, asegurador, guía, etc.

Organización de las actividades: determinación de límites espaciales y temporales de las actividades/ situaciones, anticipación de permisos oportunos, vigilancia de la climatología, preparación de mochilas dependiendo si son salidas cortas o largas, indumentaria apropiada, protocolo de accidentes, préstamo entre alumnado de material, realización previa de la ruta (confeccionar una presentación para informar de la ruta-ir sin ir-, planificación paradas,...) etc. Proyectos de curso o centro: Con la bici al cole. Parques activos. Grupos de medio natural con familias. Preparación y realización de un proyecto de acción en el medio natural (excursiones, acampadas, cicloturismo, orientación, esquí nórdico, vías verdes, etc.) de acuerdo con las posibilidades del alumnado, del centro y respetando los principios de seguridad activa y pasiva. Real ización de actividades que combinan prácticas físicas (por ejemplo: la orientación y BTT, e Tree-Athlon (carrera de larga duración-BTT-plantar y apadrinar un árbol), el esquí nórdico y la orientación, etc.) y que conllevan la preparación previa de esa tarea (cuadernos de campo, etc.) con una relación explicita con otras áreas para enriquecer el proyecto. Etc.

\begin{tabular}{|c|c|}
\hline (Cri.EF.) & (Est.EF.) \\
\hline $\begin{array}{l}\text { Cri.EF.4.1. Combinar con } \\
\text { autonomía acciones motrices para } \\
\text { decodificar información y adaptar } \\
\text { su motricidad de forma seguraala CAA } \\
\text { incertidumbre de las actividades CMCT } \\
\text { en el medio natural aprovechando } \\
\text { las posibilidades del centro } \\
\text { escolar. }\end{array}$ & $\begin{array}{l}\text { Est.EF.4.1.6. Combina con autonomía } \\
\text { acciones motrices para decodificar } \\
\text { información y adaptar su motricidad de } \\
\text { forma segura para realizar recorridos con } \\
\text { incertidumbre en el medio, aprovechando } \\
\text { las posibilidades del centro escolar, y CAA } \\
\text { modulando determinados aspectos (por CMCT } \\
\text { ejemplo, el tipo de desplazamiento, el } \\
\text { espacio, el número de señales, el grado de } \\
\text { incertidumbre, la duración, el uso o no de } \\
\text { equipos o vehículos, etc.). }\end{array}$ \\
\hline \multicolumn{2}{|c|}{$\begin{array}{l}\text { Nota: Cri.EF. = Criterios de evaluación; CC = Competencias Clave; Est.EF = Estándares de } \\
\text { aprendizaje; CAA = Aprender a aprender; CMCT = Competencia matemática y competencias } \\
\text { básicas en ciencia y tecnología. Fuente: Resolución de } 12 \text { de abril de 2016, orientaciones sobre } \\
\text { los perfiles competenciales de las áreas de conocimiento y los perfiles de las competencias clave } \\
\text { por cursos, establecidos en la O rden de } 16 \text { de junio de 2014. Anexo II: EF. En BOA de } 20 \text { de } \\
\text { junio de 2014. }\end{array}$} \\
\hline
\end{tabular}

Con todo ello, en este trabajo se expone una experiencia didáctica desarrollada con alumnado de EP en el área de EF. El objetivo con el que se ha planteado es conocer el grado de aceptación que la RA tiene en el alumnado al ser empleada como recurso didáctico.

\section{M aterial y método}

Esta investigación se fundamenta en la aplicación de una experiencia piloto, analizada desde un enfoque interpretativo, el cual, permite registrar la propia experiencia de los participantes del estudio. Esa perspectiva posibilita aproximarse al objeto de estudio desde las propias vivencias de los sujetos que constituyen dicha realidad, permitiendo de esta manera integrar la contrastabilidad y pluralidad de la realidad social (Rey, 2014). 


\section{Contexto}

El programa de intervención aplicado se llevó a cabo en el CEIP Cortes deAragón (Zaragoza, España). Compuesto por ocho sesiones prácticas, todas ellas centradas dentro del dominio de acción motrizAFM N, concreta mente en los contenidos de orientación y escalada, se tituló Explora tu mundo.

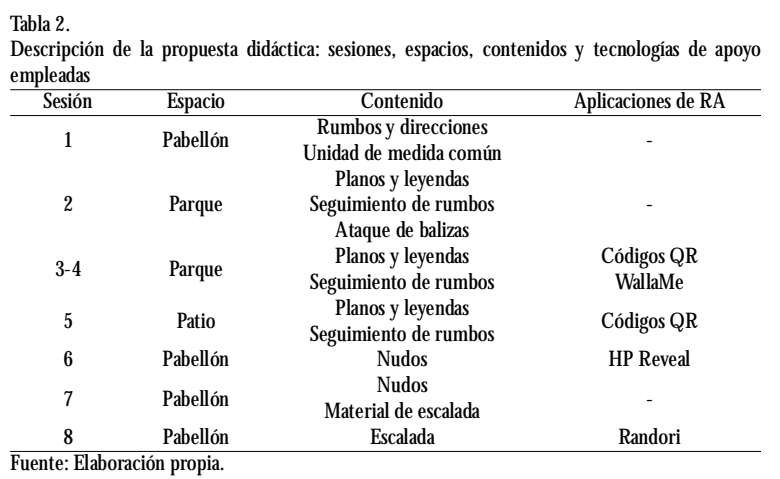

En la tabla 2 se han destacado las herramientas TIC utilizadas, a saber: WallaMe, lector de códigos Q R, HP Reveal y Randori. Todas ellas, salvo HP Reveal, se pueden descargar de forma gratuita en cualquier dispositivo móvil. La aplicación geolocalizada WallaMe (figura 1) permite dejar mensajes ocultos, que solo pueden ser descubiertos al situarse en la ubicación exacta. Se utilizó durante una carrera de orientación realizada en grupos para el descubrimiento de las balizas. La lectura de códigos QR se empleó durante el rally fotográfico, permitiendo visualizar la zona en la que se debían buscar las siguientes pistas. HP Reveal (figura 2) es una aplicación cuyo funcionamiento se basa en la lectura de un marcador, unaimagen, sobrelaque se proyectaun vídeo. Se utilizó para introducir el contenido de la escalada.
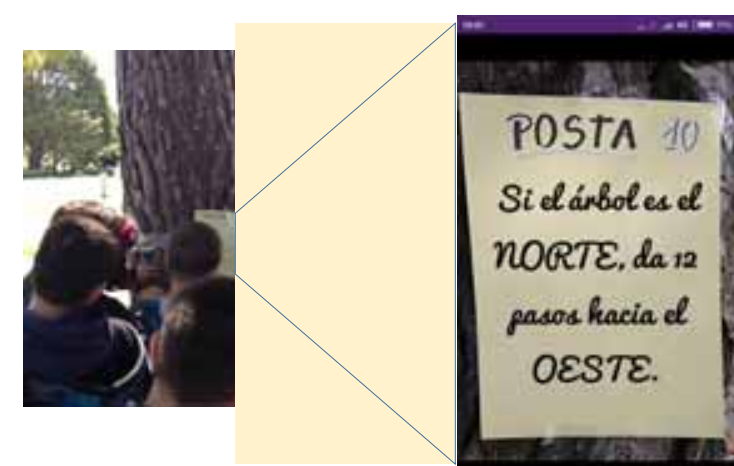

Figura 1. Ejemplo de material empleado en las sesiones de orientación. Fuente: Elaboración propia.

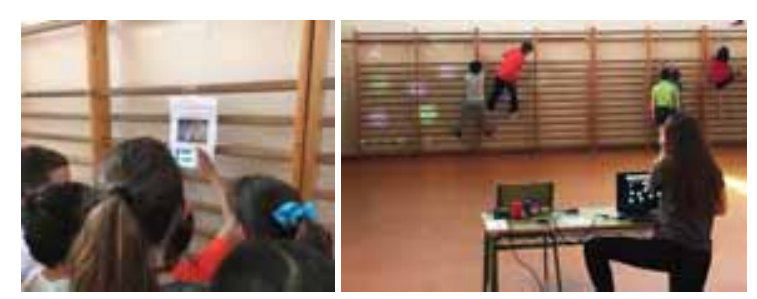

Figura 2. Ejemplo de material empleado en las sesiones de escal ada. Fuente: Elaboración propia.
Con la cámara del teléfono móvil se enfocaba a distintas imágenes correspondientes a los diferentes tipos de escalada (escalada en hielo, BigWall, etc.) en las cuales se enlazaron videos con las técnicas específicas para cada modalidad. Sin embargo, esta aplicación actualmente no está en funcionamiento, por lo que se sugiere el uso de LinkReader como recurso alternativo. Por último, mediante la aplicación Randori (figura 2), se proyecta ron en las espalderas una serie de juegos y actividades encaminados a la iniciación sobre los agar res y desplaza mientos.

\section{Participantes}

La muestra seleccionada, intencionada y de carácter no aleatorio, quedó constituida por 37 de los 40 estudiantes de quinto curso de EP (10-11 años).

Para la selección de los participantes se aplicaron dos criterios: el grado de presencia (asistencia al 80\% de las ocho sesiones) en las sesiones prácticas de EF impartidas a lo largo de la unidad didáctica «explora tu mundo»; y la entrega del diario de prácticas de las sesiones. Se excluyeron tres individuos, dos por incumplimiento del primero de los criterios, y uno por el segundo. Ninguno de los participantes tenía experiencia previa en el uso de la RA en el ámbito escolar.

Los participantes y sus familiares/ tutores legales recibieron una explicación completa y clara sobre los objetivos del proyecto y su diseño. Se contó con las autorizaciones pertinentes para que sus diarios de prácticas se utilizaran para la investigación. U na miembro del equipo de investigación fue la profesora de EF que impartió la unidad didáctica, por lo tanto, se debe tener en cuenta la posible influencia de la relación profesional profesor/ aralumno/ a. Esta relación también implica un conocimiento significativo de los participantes, facilitando la resolución de cualquier incidente que surja en el proceso de investigación (Elliot, 2000).

\section{Instrumentos}

La recogida de datos se realizó a través de diarios de prácticas que fueron elaborados por los participantes. Éstos accedieron de forma voluntaria y se les informó de los objetivos de la investigación. Los diarios estaban pautados mediante una serie de cuestiones para concretar la satisfacción y la insatisfacción del alumnado sobre la incorporación de la RA.

Una vez recogidos los diarios, se procedió al análisis de contenido. Para ello, se elaboró un sistema de categorías (adaptado de Canales-Lacruz \& Ponzán-Frisa, 2016) con una única dimensión de análisis - grado de 
satisfacción de la RA- y dos categorías, una vinculada con la satisfacción y la otra con la insatisfacción. Las subcategorías son el último nivel de concreción, relativas a los diferentes motivos que han desencadenado las sensaciones correspondientes a las categorías (tabla 3).

\begin{tabular}{|c|c|c|}
\hline Dimensión & Categorías & Subcategoría \\
\hline \multirow[t]{2}{*}{$\begin{array}{l}\text { 1. Grado de satisfacción por el uso } \\
\text { de la realidad aumentada }\end{array}$} & 1.1. Satisfacción & $\begin{array}{l}\text { 1.1.1. Intrigante } \\
\text { 1.1.2. Utilidad } \\
\text { 1.1.3. Colaboración } \\
\text { 1.1.4. Novedad } \\
\text { 1.1.5. Realidad } \\
\text { 1.1.6. Gusto por la tecnología } \\
\text { 1.1.7. O tros } \\
\text { 1.1.8. Sin especificar }\end{array}$ \\
\hline & 1.2. Insatisfacción & $\begin{array}{l}\text { 1.2.1. Falta de utilidad } \\
\text { 1.2.2. Fallos aplicación } \\
\text { 1.2.3. Falta de novedad } \\
\text { 1.2.4. Disgusto por la tecnología }\end{array}$ \\
\hline
\end{tabular}

Se siguió un proceso inductivo y deductivo para la elaboración del sistema de categorías. Para ello, se partió de un modelo teórico sobre el objetivo de la investigación y se fue configurando ad hoc en función de los diarios de los estudiantes. El proceso se ha realizado tomando como referencia el objetivo del estudio, además de presentar los criterios de exhaustividad y exclusividad tanto en las categorías como en las subcategorías (Heineman, 2003).

\section{Procedimiento}

Los participantes cumplimentaron el diario de prácticas al finalizar cada sesión de las ocho que componían la unidad didáctica. Cadasesión finalizaba cinco minutos antes y así podían apuntar lo más relevante de lo experimentado. Posteriormente se realizaba la redacción final fuera del aula.

El diario formó parte de la evaluación de la asigna tura. Se valoró exclusivamente la profundidad de las descripciones, calificadas como Apto o No apto. No se tuvo en cuenta, por tanto, la valoración de las tareas ni la de los procedimientos pedagógicos. Los datos fueron recogidos por la propia docente del programa de intervención.

Bardin (2002) propone tres fases para organizar el procedimiento una vez se hayan recogido los datos: preanálisis, explotación del material y tratamiento e interpretación de datos.

a) En la fase preanálisis se confeccionó el sistema de categorías para llevar a cabo el análisis de contenido de los diarios. Primero se leyeron todos y se diseñó un primer boceto adaptándolo de Canales-Lacruz y PonzánFrisa (2016). U na de las decisiones tomadas fue la crea ción de una subcategoría denominada 1.1.8. Sin especificar que incorporaba aquellos fragmentos que describían la satisfacción del uso de la RA, pero que no detaIlaban 0 argumentaban dicho gozo. Debemos recordar que los participantes del estudio tienen edades comprendidas entre los 10 y los 11 años y, por lo tanto, en muchas ocasiones se limitan a describir la sensación de forma superficial, con valoraciones como «me gusta» 0 «me ha parecido bien». Posteriormente se efectuó una prueba piloto sobre una submuestra seleccionada al azar (30\% de la muestra). En dicha prueba piloto se aplicó un test de confiabilidad en un cál culo de acuerdo entre doscodificadoresindependientes. Se utilizó el coeficiente de kappa de Cohen como medida de concordancia $(k=.89)$.

b) En la explotación del material se codificaron todos los diarios, seleccionando en primer lugar los fragmentos a categorizar y posteriormente se codificaron según la subcategoría que le correspondiese.

c) El tratamiento e interpretación de los resultados se llevó a cabo utilizando el programa informático Q SR-NVIVO 11, diseñado para el análisis de datos en investigaciones basadas en métodos cual itativos. Esta herramienta permite indizar los fragmentos seleccionados según el sistema de categorías empleado y posibilita unos índices cuantitativos de cada una de las subcategorías, en cuanto al número de párrafos, su porcentaje con respecto a los otros indicadores o número de informantes que componen la compilación.

\section{Resultados}

Se han codificado un total de 143 referencias, de las cuales, 125 están relacionadas con la satisfacción - categoría 1.1. - y 18 con la insatisfacción - categoría 1.2. - Es decir, el 87,4\% de las referencias describen la satisfacción por el uso de la RA durante el desarrollo de las situaciones de escalada y orientación. La exposición detallada del número de referencias y el porcentaje de las mismas nos indican las preferencias de los informantes por cada uno de los temas anal izados. Por lo tanto, los participantes han tenido gran interés en describir la intriga y la utilidad de la realidad aumentada utilizada paralassesiones de EF. Sin embargo, otros aspectos como la colaboración o la novedad han sido de menor interés para ellos.

En la figura 3 se puede apreciar el número de referencias por subcategoría. Las más numerosas pertenecen a la categoría satisfacción (1.1.) y son: 1.1.1. Intrigante, 1.1.2. Utilidad y 1.1.8. Sin especificar. En esta 
última subcategoría se han incluido todas las referencias que no especifican el motivo de la satisfacción por el uso de la RA, frases tales como «me ha gustado», «ha sido muy chulo», «me ha parecido genial», etc. Dichas ideas fueron codificadas al considerar que describían la satisfacción percibida por el uso de la RA, aunque no se incorporara 0 argumentara el motivo de esa percepción positiva.

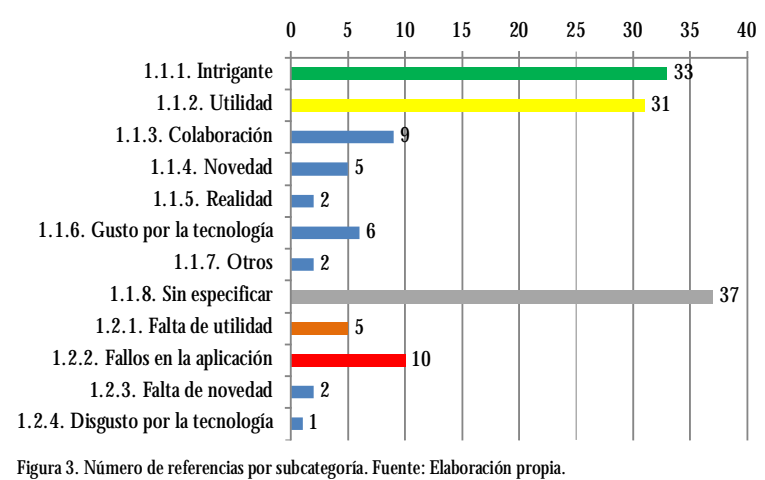

A continuación, se exponen los resultados específicos relativos a las dos categorías señaladas en la definición del objeto de estudio. Se acompañan de fragmentos textual es obtenidos a través de los diarios. Los nombres de los alumnos han sido modificados para garantizar su anonimato.

\section{La intriga y la utilidad como principales moti- vos de satisfacción}

La intriga (subcategoría 1.1.1.) ha sido uno de los motivos con mayor número de referencias (33 referencias) de la muestra. De esta forma, se han encontrado reflexiones como la de Antonio, destacando el papel esencial del uso de la tecnología y de la RA para fomentar esa sensación que, a su vez, favorece la implicación en el desarrollo de las actividades: «La Realidad Aumentada era genial, porque teníamos que llegar casi y la profe tenía que enfocar para que salieran las pistas y encontrar el código. Eso sí que era ser un pirata busca tesoros o un detective». Susana refuerza este argumento: «Prefiero haber usado la realidad aumentada porque así si querías ver el mensaje necesitabas el móvil y si no, no podías verlo y era más intrigante».

La mayoría de los testimonios coinciden en resaltar el carácter oculto y casi mágico de las aplicaciones de la RA. Por ejemplo, M arcos describe: «enfocabas la cartulina y salían unas coordenadas; era muy emocionante». También para Silvia es excitante «el que la fotogra fía se convertía en un vídeo». En esta misma línea, Luis señala que le resultó «impresionante como de un simple folio con una foto puede salir un video».
Del mismo modo, la utilidad (subcategoría 1.1.2.) ha sido muy referenciada (31 referencias). En ella, los participantes destacan principalmente la ventaja que supone la aplicación de la RA para el desarrollo de las situaciones motrices. Más concretamente, dicha utilidad se ha destacado para resolver las tareas de orienta ción en el parque, ya que «nos facilitó encontrar las pistas sin ningún problema» (Marta), argumento compartido por más estudiantes: «M e ha parecido útil la aplica ción, he preferido usarla porque te dirigía bien» (Isa bel); «En la carrera la Realidad Aumentada nos facilitó encontrar las pistas sin ningún problema. La realidad aumentada fue un éxito» (J esús).

También para las tareas de escalada «la realidad aumentada me encantó porque nunca lo había visto con mis ojos y comprendí mucho mejor los tipos de escala da» (Julio); «Prefiero usar la realidad aumentada porque así ves cómo se hace escalada y lo que se utiliza para hacerla» (José Luis); «Demuestras como explicar sin ordenador, ni pantalla, como se hacen las cosas en movimiento, no en una foto solo» (Beatriz).

0 tros motivos con menor número de referencias son la colaboración (subcategoría 1.1.3.), la novedad (subcategoría 1.1.4.), la realidad (subcategoría 1.1.5.) y el gusto por la tecnología (subcategoría 1.1.6.). Los testimonios de la colaboración se refieren alainteracción social que desencadenael uso de las aplicaciones, ya que, cada dispositivo móvil debe compartirse con todos los miembros del grupo, favoreciéndose el trabajo en equipo: «se necesitaba la sincronización del compañero» (Tomás). Con respecto a la novedad, se relata la curiosidad que despierta el poder experimentar con situaciones nuevas e innovadoras: "también al ver el video y escalar parecía de verdad y daba como miedo» (M aría). También, el hecho de que las aplicaciones utilizadas generan escenarios de realidad ha sido un motivo de satisfacción, categoría que se complementa con argumentos a favor del gusto intrínseco por el uso de la tecnología: «M e gustó utilizar la aplicación, me parece una motivación para aprender» (Luisa).

\section{Los fallos en la tecnología como el principal motivo de insatisfacción}

A pesar de que el número de referencias recogidas en la categoría insatisfacción (1.2.) es mucho menor, se debe comentar los motivos que los ha suscitado. Los fallos en las aplicaciones (subcategoría 1.2.2.) ha sido el más numeroso, con 10 referencias, las cuales describen los problemas técnicos que han ocasionado en algún momento las aplicaciones. Por ejemplo, Pedro detalla 
«que la realidad aumentada no me ha gustado mucho porque era bastante lenta, y en al gunas pistas no aparecía ningún mensaje oculto». También «el uso de la aplicación Randori no ha estado bien porque en las espalderas no se veía nada». Se han encontrado testimonios que referencian errores tecnológicos asociados a la conectividad necesaria para el correcto funciona miento de estas aplicaciones. Así, José señala que «lo único que no me gustó del todo fueron los códigos $Q R$ porque perdíamos tiempo cuando fallaba la aplicación». Atendiendo a otras aplicaciones empleadas en esta propuesta didáctica, Alejandro indica que «a veces, faltaban datos y no se me cargaban bien».

0 tro de los motivos de insatisfacción es la falta de utilidad (subcategoría 1.2.1., con cinco referencias) experimentada en algunos momentos, y «es que no me gustó porque encontrábamos los sobres mucho antes que pudiéramos descifrar el mensaje con la aplicación» (María). Dos referencias señalan la falta de novedad (subcategoría 1.2.3.) que suponen las aplicaciones utilizadas, y «es que ya había utilizado códigos QR otras veces» (Bruno).Y, por último, cabe destacar el disgusto que genera el uso de la tecnología (subcategoría 1.2.4.) en un alumno que expone: «No me gustan las nuevas tecnologías porque a mí me gusta más hacerlo a la vieja usanza y aún encima había al guna que otra tarjeta que se leía a simple vista entonces perdía la gracia» (Raúl).

\section{Discusión}

El objetivo principal con el que se ha planteado este estudio era valorar la percepción que tenía el alumnado deEP sobreel uso de la RA como recurso metodológico en una propuesta metodológica que integra la RA en las AFM N. A grandes rasgos, esta tecnología ha sido recibida de forma muy positiva, favoreciendo la motivación y la implicación de los estudiantes, coincidiendo con los resultados mostrados en estudios previos (Ayala, Escaravajal, Otálora, Ruiz \& Nicolás, 2017; Cabero \& Barroso, 2016). La novedad y el gusto por el uso de la tecnología son al gunas de las razones aportadas, encontrando así una utilidad práctica a la RA en el aula. Esta utilidad también ha sido señalada por futuros maestros en las experiencias planteadas en diferentes contextos (entre otros, Fernández Robles, 2017; Marín-Díaz, Sampedro \& Muñoz, 2017; San Pedro, Villalustre \& Herrero, 2019). Los resultados encontrados inciden en la facilidad de uso de las aplicaciones empleadas y la ayuda que suponen para el desarrollo de las actividades de enseñanza-aprendizaje. La gran mayoría de partici- pantes afirma estar dispuesto a incorporar esta tecnología en su futura actividad como maestros y maestras. Sin embargo, habría que contar con un número mínimo de dispositivos en el aula, hecho que puede convertirse en una limitación en el caso de la etapa de EP.

Respecto a las fuentes de insatisfacción señal adas en nuestro estudio, el principal motivo encontrado son los fallos puntuales de funcionamiento de las aplicaciones, muchas veces derivados de la conectividad de la red, coincidiendo con lo referenciado por San Pedro, Villalustre y Herrero (2019). De esta forma, el uso de dispositivos móviles en el aula pueden ser recursos que deriven en una dificultad añadida para el correcto desarrollo de las actividades. Especialmente, en el caso de las AFM N, si éstas se llevan a cabo en un entorno en el que no se pueda contar con la totalidad de la cober tura de red.

Los contenidos desarrollados en esta experiencia pertenecen al área de $\mathrm{EF}$, concretamente, al bloque de AFM N - orientación y escalada- . El estudio de Kajastilla, Holsti y Hämälainen (2016) vinculado con la escalada en contextos no educativos analizó las percepciones de losusuarios, siendo sus resultados coincidentes con nuestro estudio. Se destaca la versatilidad a la hora de diseñar nuevas rutas, sin necesidad de modificar las presas manualmente. La aplicación Randori utilizada en nuestro estudio permite esto mismo, modificar las vías y los recorridos desde el ordenador, sin necesidad de perder tiempo de práctica. Los estudiantes han señalado de manera positiva que el planteamiento combinado con la aplicación HP Reveal facilita la experiencia inmersiva y el conocimiento de diferentes modal idades de escalada, complementando así la explicación a nivel teórico. De esta forma, y de acuerdo con Díaz (2020), la preparación previa tanto de los contenidos como de la selección de aplicaciones más adecuadas para desarrollarlos aparece como una necesidad real a la hora de implementar las TIC en el aula. Además, es posible que algunas de ellas requieran formación en su uso. Para el caso del alumnado, habría que destinar ese tiempo de familiarización dentro de las propuestas didácticas para asegurar una adecuada utilización de estos recursos didácticos.

En nuestro estudio, al gunos de los estudiantes de EP también han afirmado en sus diarios haber adquirido conocimientos sobre la búsqueda y ataque de balizas, lo que sugiere que este tipo de contenidos es adecuado para todas las etapas formativas. No estamos abogando por sustituir el contacto con el medio natural por la tecnología ni poner a ésta como objetivo de aprendizaje 
en el área de EF. N os referimos a considerarla como un recurso didáctico más que ayude a los estudiantes a implicarse en su propio proceso de aprendizaje, pero sin que puedasustituir auna prácticamotriz real en el medio natural, tal y como sugieren Gallego-Lemaet al. (2017a), dado que este dominio de acción motriz se fundamenta en la interpretación y adaptación a la incertidumbre que ofrece el propio medio en el que se desarrolla la actividad física.

\section{Conclusiones}

La valoración realizada por el alumnado en relación al uso de la RA como recurso didáctico para el trabajo de las actividades físicas en el medio natural ha sido positiva. Como aspectos principales destacan la intriga y la sorpresa por encontrar el material proyectado. Además, se considera útil en el sentido en que favorece el conocimiento sobre nuevos entornos de aprendizaje sin necesidad de desplazarse hasta ellos. Por último, algunos estudiantes creen que esta tecnología desarrolla actitudes de colaboración por el propio diseño con el que se ha planteado la experiencia.

Por otra parte, se han señalado ciertos elementos negativos. El primero de ellos, asociado a los fallos tecnológicos que puntual mente se han encontrado al utilizar las aplicaciones. El segundo, el propio diseño de la actividad de orientación, debido a que se podía acceder a algunas pistas omitiendo el uso de estas aplicaciones.

Para finalizar, y de acuerdo con M esquida \& Pérez (2017), consideramos que son necesarios más estudios específicos en los que se analice la conveniencia de la RA en la aplicación de diferentes propuestas formativas. Nos referimos tanto a la tecnología en sí misma como a estudios sobre el uso de aplicaciones concretas para determinar su pertinencia en las diferentes áreas de conocimiento. En el caso de la etapa de EP, puede suponer un recurso idóneo para el desarrollo de la Competencia Digital en el alumnado. Además, la literatura previa otorga especial importancia al uso de la RA para favorecer la construcción de contextos de aprendizaje más complejos y motivadores para el alumnado. Este hecho es particularmente interesante dentro del área de EF, sobre todo, en el caso de las AFM N, dadas sus características y que, en ocasiones pueden conllevar reticencias a ser desarrolladas fuera del centro. Especialmente, en un momento como en el que nos encontramos, en el que la emergencia sanitaria pueda reforzar ese impedimento a la hora de salir del centro. La RA como recurso didáctico puede contribuir a superar algunas de esas limitaciones señaladas, sin olvidar que la esencia del área de EF es el movimiento, la competencia motriz. Por tanto, la RA puede considerarse como un facilitador, un elemento introductorio a las AFMN, pero que segura mente pueda resultar insuficiente si posteriormente no se trasladan los conocimientos adquiridos a una práctica real en el entorno natural.

\section{Referencias}

Amaya, L. P.; \& Santoyo, J. S. (2017). Evaluación del uso de la realidad aumentadaen laeducación musical. CuadernosdeM úsica,Artes/isualesy Artes Escénicas, 12(1), 143-157. https:/ / doi.org/ 10.11144/ Javeriana.mavæel2-1.uræ.

Ayala, J. D.; Escaravajal, J. C.; Otálora, F. J.; Ruiz, Z; \& Nicolás, J. (2017). Carreradeorientación con códigos $Q \mathrm{R}$ en Educación Física. Espiral. Cuadernosdel Profesorado,10(21), 132-139, 2017.

Azuma, R. (1997). A Survey ofAugmented Reality. PresenceiTleoperatorsand Virtual Environments, 6(4), 355-385. https:/ / doi.org/ 10.1162/ pres.1997.6.4.355.

Bæena, A.; \& Graneros, A. (2015). Efectosdelasactividadesen lanatura lezaen lapredicción delasatisfacción delaEducación Física. Retos, 28, 9-14.

Bardin, L. (2002). Análisisdecontenido. Madrid:Akal.

Cabero, J.; \& Barroso, J. (2016). Posibilidades educativas de la realidad aumentada. N ew Approachesin Educational Research, 5(1), 46-52. http:/ / dx. doi. org/ 10.7821/ næer.2016.1.140.

Calabuig-Moreno, F.; González-Serrano, M. H.; Fombona, ..; \& García Tascón, M. (2020). Theemergency of technologyin Physical Education: A general bibliometricAnalysiswith afocuson virtual and augmented reality. Sustainability, 12, 2728. https:// doi.org/ 10.3390/ su12072728.

Caldeiro-Pereira, M. C.;Yot-Domínguez, C.; \& Castro-Zubizarreta, A. (2018). Detección debuenasprácticas docentes deuso de dispositivos móviles en Primaria a través del análisis documental. Prisma Social, Revista deinvestigación social, 20, 58-75.

Canales-Lacruz, l.; \& Ponzán-Frisa,A. (2016). Motivos de satisfacción e insatiffacción del alumnado deeducaciónfísicaen situacionesmotrices debéisbol. Revista deEducación Física, 34(3), 1-8.

Castañeda, L.; Gutiérrez, l.; \& Román, M. M. (2014). Enriqueciendo la realidad: realidad aumentada con estudiantes de Educación Social. @ tic, revista d'innovacióeducativa, 12, 15-25. https/ / doi.org/ 10.7203/ attic. 12.3544.

Castro, N. ; \& Gómez, l. (2016). Incorporación de los códigosQ R en la Educación Físicaen Secundaria. Retos, 29, 114-119.

Díaz, J. (2020). Retosy oportunidades delatecnologíamóvil en laeduca ciónfísica. Retos, 37, 763-773.

Elliot, J. (2000). El cambio educativo desde la investigacion-accion. Madrid: Morata.

Escaravajial, J. C.; \& Baena-Extremera, A. (2019). Lasaplicacionestecnológicas en el deporte de orientación y en educación física. Habilidad motriz, 53, 28-40.

Estebanell, M.; Ferrés, J.; Cornellas, P.; \& Codina, D. (2012). Realidad aumentaday códigosQ R en educación. En]. Hernández; M. Pennesi; D. Sobrino; \&A.Vázquez(Coords). Tendenciasemergentesen educación con TIC (pp. 277-300). Barcelona: Espiral.

FernándezRobles, B. (2017). Factoresqueinfluyen en el uso yaceptación de objetos de aprendizajedereal idad aumentadaen estudiosuniversi- 
tariosdeEducación Primaria. ED M ETIC, Revista deEducación M ediática yTIC,6(1), 203-220. https:/ / doi.org/ 10.21071/ edmetic. v6i1.5815.

Fombona, J.; \& Pascual, M. A. (2017). La producción científica sobre Realidad Aumentada, un análisis de la situación educativa desde la perspectivaSCOPUS. ED M ETIC, Revista deEducación M ediática yTIC, 6(1), 39-61. https:/ / doi.org/ 10.21071/ edmetic. v6i1.5807.

Fombona, ..; Pascual, M. A.; \& M adeira, M. F. (2012). Realidad aumenta da, unaevolución delasaplicacionesdelosdispositivosmóviles. PíxelBit. Revista deM ediosy Educación, 41, 197-210.

Gallego-Lema,V.; M uñoz-Cristóbal, J.A.;A rribas-Cubero, H. F.; \& Rubia Avi, B. (2017a). Laorientación en el medio natural: aprendizajeubicuo medianteel uso detecnología Movimento, 23(2) 755-750. https:/ / doi.org/ 10.22456/ 1982-8918.71682.

Gallego-Lema,V.; M uñoz-Cristóbal,J.A.;A rribas-Cubero, H. F.; \& Rubia Avi, B. (2017b). RecursosTIC en el medionatural. Tándem, 58, 65-70.

García, O.; \& Ramos, F. (2016). Lasnuevas tecnologías en el marco de aprendizajesignificativo. En R. Roig-Vila(Ed.). Tecnología, innovación e investigación en losprocesosdeenseñanza-aprendizaje(p. 510-516). Barcelona: 0 ctædro.

Gehris, .; M Mers, E.; \&W hitaker, R. (2012). Physical activity levelsduring adventure-physical eduction lessons. European Physical Education Review, 18, 245-257. https:/ / doi. org/ 10.1177/ 1356336X12440365.

Heinemann, K. (2003). Introducción a la metodología dela investigación empírica. Barcelona: Paidotribo.

Izquierdo,A. (2013). CódigosQ R flexibles: un proyecto con dispositivos móvilesparael trabajo decalentamiento en Educación Física. EmásF, Revista digital deEducación Física, 23, 53-71.

Kajastila, R.; H olsti, L.; \& Hämäänen, P. (2016).TheAugmented Climbing Wall. In: Conference on H uman Factors in Computing Systems' 16 (p. 758769). New York: ACM. http:// dx.doi.org/ 10.1145/ 2858036.2858450.

Kim, D.; Chun, H.; \& Lee, H. (2014). Determining the Factors that InfluenceC ollegeStudents' Adoption of Smartphones. Association for Information Science \& Technology, 65(3), 578-588. https:/ / doi.org/ 10.1002/ asi. 22987.

Klein, A.; \& Carniceli, S. (2009). Actividades físicas de aventura en la naturaleza(AFAN) yacademiasdegimnasia: motivosdeadhesión y beneficiosderivadosdelapráctica. M ovimento, 15(3), 187-208. https:/ / doi.org/ 10.22456/ 1982-8918.4917.

Lánez, B.; Chocarro De Luis, E.; Busto, J. H.; \& López, J. (2018). A portaciones de la Realidad Aumentada en la inclusión en el aula de estudiantes conTrastorno del EspectroAutista. EDM ETIC, Revista de Educación Mediática yTIC,7(2), 120-134. https:/ / doi.org/ 10.21071/ edmetic.v7i2.10134.

Leiva, J. J.; \& Moreno, N. M. (2015). Tecnologías de geolocalización y RealidadAumentadaen contextoseducativos: experienciasy herra mientas didácticas. Revista científica deopinión y divul gación Didáctica, Innovación y Multimedia (DIM), 31, 1-18.

LO MCE, Ley O rgánica8/ 2013, de9 dediciembre, paralamejoradela calidad educativa. Publicadaen el Boletín 0 ficial del Estado el 10 de diciembrede 2013.

Maquilón, J.; Mirete,A. B.; \&Avilés, M. (2017). LaRealidad aumentada (RA). Recursos y propuestas para la innovación educativa. Revista Electrónica Interuniversitaria deFormación del Profesorado, 20(2), 183-203. https:/ / doi.org/ 10.6018/ reifop/ 20.2.290971.

Marín-Díaz,V. (2018). La realidad aumentadaal servicio de lainclusión educativa. Estudio decaso. RetosXXI, 2(1), 60-72. https: / / doi.org/ 10.33412/ retoxxi.v2.1.2060.

Marín-Díaz, V.; Sampedro, B. E.; \& Muñoz, J. M. (2017). La realidad aumentadaen el aulade Educación Primaria. Observatório, 3(5), 634668. http:/ / dx. doi.org/ 10.20873/ uft.2447-4266.2017v3n5p634.
M artín-Sabarís, R.; \& Brossy-Scaringi, G. (2017). Larealidad aumentada aplicadaal aprendizajeen personascon Síndromede D own: un estudio exploratorio. Revista Latina de Comunicación Social, 72, 737-750. https: / / doi.org/ 10.4185/ RLCS-2017-1189.

Mesquida, M. C.; \& Pérez,A. (2017). Estudio deappsderealidad aumentada para su uso en campos de aprendizaje en un entorno natural. EDUTEC. Revista Electrónica deTecnología Educativa, 62, 19-33. dx. doi.org/ 10.21556/ edutec. 2017.62.1017.

M oreno, E.; \& Pérez García, A. (2017). La realidad aumentada como recurso didáctico paralosfuturosmaestros. Etic@ net, Revista científica electrónica de Educación y Comunicación en la Sociedad del Conocimiento, $17(1), 42-59$.

Moreno,A. .; Rodríguez, C.; Ramos, M.; \& Sola, J. M. (2020). Interésy motivación del estudiantado de Educación Secundariaen el uso de Aurasmaen el auladeEducación Física. Retos, 38, 333-340.

Pedraza, C. E.; Amado, O. F.; Lasso, E.; \& Munévar, P. A. (2017). La experiencia de la Realidad Aumentada (RA) en la formación del profesorado en laU niversidad N acional A biertaya a istancia. UNAD Colombia. Píxel-Bit. Revista deM ediosy Educación, 51, 111-131. http:/ / dx. doi.org/ 10.12795/ pixelbit. 2017.i51.08.

Peñarrubia, C.; Guillén, R.; \& Lapetra, S. (2016). Las actividades en el medio natural en Educación Física, ¿teoría o práctica?Cultura, Ciencia y Deporte, 11(31), 27-36. http:/ / dx. doi.org/ 10.12800/ ccd.v11i31.640.

Peñarrubia, C.; Q uintas,A.; Rapún, M.; \& Fal cón, D. (2018). Didácticalas actividades en el medio natural mediante $m$-learning y realidad aumentada en el Grado de Magisterio en Educación Primaria. Revista Internacional deD eportesColectivos, 35, 34-42.

PérezAmate, M. M.; \& Pérez O rdás, R. (2012). Propuesta de unidad didáctica sobre Geocaching: en busca del tesoro escondido. EmásF, revista digital deEducación Física, 19, 155-172.

Pérez-López, D. (2015). e-JU NIO R : sistemaderealidad aumentadapara el conocimiento del medio marino en Educación Primaria. Revista QUID, 24, 35-42.

Prendes, C. (2015). Realidad aumentaday educación: análisisdeexperienciasprácticas. Píxel-Bit. Revista deM ediosy Educación, 46, 187-203. http:/ / dx. doi.org/ 10.12795/ pixelbit.2015.i46.12.

Rey,A. (2014). Ciencia y motricidad. Epistemología delascienciasdela actividad física y el deporte. Madrid: Dykinson.

Resolución de 12 deA bril de 2016, del Director General dePlanificación yFormación Profesional por laquese ofrecen orientacionessobrelos perfilescompetencialesdelasáreasdeconocimiento ylosperfilesdelas competenciasclave por cursos, establecidosen laO rden de16 dejunio de2014, delaConsejeradeEducación, U niversidad, Culturay Deporte, por laqueseapruebael currículo delaEducación Primariay se autorizasu aplicación en loscentrosdocentesdelaComunidadAutónomadeAragón.

San Pedro, M. B.; Villalustre, L.; \& Herrero, M. (2019). Diseño de un itinerario aumentado einterdisciplinar paralaformación demaestros deeducación primaria EDUTEC. Revista Electrónica deTecnologíaEducativa, 68, 54-69. https:/ / doi.org/ 10.21556/ edutec. 2019.68.1293.

Toledo, P.; \& Sánchez, J. M. (2017). Realidad aumentadaen Educación Primaria: efectossobreel aprendizaje. Revista Latinoamericana deTenología Educativa, 16(1), 79-92. https:/ / doi.org/ 10.17398/ 1695288X.16.1.79.

Villalustre, L.; Del Moral, M. E.; Neira, M. R.; \& Herrero, M. (2017). Proyecto ACRA: Experiencias didácticas en ciencias con realidad aumentadaen losnivelespre-universitarios. EDUTEC. Revista Electrónica de Tecnología Educativa, 62, 1-18. dx.doi.org/ 10.21556/ edutec. 2017.62.1009. 